\section{"La letra con raza, entra" Racismo, textos escolares y escritura pedagógica afrocolombiana}

\author{
"A letra com raça entra" \\ Racismo, livros escolares \\ e escritura pedagógica \\ afrocolombiana
}

\section{Resumen}

Han trascurrido diecisiete años desde la promulgación de la Ley 70 para comunidades negras en Colombia. En este lapso de tiempo, algunas investigaciones demuestran que el discurso racista en los textos escolares de Ciencias Sociales se mantiene vigente. Como forma de contrarrestar sus efectos, han surgido manuales y textos escolares, producidos por autores afrocolombianos y dirigidos a un amplio sector educativo. El artículo propone un primer plano de reconocimiento y análisis en torno a este nuevo libro escolar, cuya escritura pedagógica apunta a dignificar la afrocolombianidad.

\section{Palabras clave}

Textos escolares, afrocolombianidad, racismo, saberes escolares, políticas del conocimiento.

\section{Abstract}

Since promulgation of law 70 seventeen years ago for black people communities in Colombia, some research projects demonstrate that the racist speech in some school books of Social Sciences has been kept. As a way of counteracting their effects, some other school books and manuals have emerged, produced by AfroColombian authors and directed to a wide ranging educational group. This article proposes a first view of recognition and analysis around to this new school book, which pedagogic writing is pointed to dignify the Afro-Colombian status.

\section{Key words}

School books, afro-Colombian status, racism, school knowledge, policies of knowledge.

\section{Resumo}

Há dezessete anos foi promulgada a Lei 70 para comunidades negras na Colômbia. Neste período, algumas pesquisas mostram que o discurso racista nos livros escolares de estudos sociais está em vigor. Como uma forma de contrariar os seus efeitos, alguns autores colombianos tem escrito manuais e livros escolares, destinados a um grande sector da educação. 0 artigo propõe reconhecimento e análise sobre este novo livro escolar que visa dignificar a afrocolombianidade.

\section{Palavras-chave}

Livros escolares, afrocolombianidade, racismo, conhecimento escolar, políticas do conhecimento.

Fecha de recepción: 6 de mayo de 2011 Fecha de aprobación: 24 de junio de 2011

Pedagogía y Saberes No. 34 Universidad Pedagógica Naciona Facultad de Educación. 2011, pp. 61 - 73 


\section{Del racismo en los textos escolares de Ciencias Sociales}

Olvidaba decir que en aquellos tiempos, en vista de que no habían podido evitar que se abrieran las escuelas, trataron de intimidar a los negritos con eso de que "la letra, con sangre entra". Con esto buscaban que los hijos del pueblo le cogieran odio al estudio. Contra ellos se pusieron de moda los palmetazos, los reglazos, los fuetazos y los rejazos con cuero de vaca o nudosas varitas de totumo.

\section{Miguel A. Caicedo}

...el racismo hace parte de la historia de la escuela, y la escuela hace parte de la historia del racismo.

\section{Elizabeth Castillo Guzmán}

$\mathrm{E}$ racismo en Colombia constituye un fenómeno estructural ${ }^{1}$ que se expresa en diferentes escenarios de la vida cotidiana e institucional; asimismo, opera a través de concepciones y prácticas de inferiorización respecto de las poblaciones afrodescendientes, su historia y sus culturas. La escuela se constituye en una de las instituciones donde esta ideología de la superioridad racial se ha reproducido con gran potencia, pues, desde sus orígenes y a lo largo de casi dos siglos, en su interior se anclaron prácticas de saber sostenidas en la idea de la inferioridad moral e intelectual de los descendientes de africanos. El racismo entendido de este modo, transita como parte de los contenidos de la socialización primaria que acontece en la escuela para un amplio conjunto de la población infantil; por esta razón se reconoce como un fenómeno que marca el mundo de los valores y las creencias moralmente asumidas en esta etapa de la vida. De este modo podemos aceptar que la visión inferiorizada de lo negro, lo africano y/o

1 Para este análisis retomo la tipología propuesta por Restrepo (2008) sobre racismo manifiesto y racismo latente, pues son dos nociones muy útiles para entender este fenómeno en el ámbito de la escuela. Para Restrepo, el racismo manifiesto es "la amalgama de los enunciados, percepciones y prácticas que son explícitamente racistas; es decir, que pueden ser fácilmente reconocidas como racistas por quien las agencia o por quienes son testigos o víctimas de este racismo... este racismo trabaja en la superficie del discurso y de los comportamientos de tal manera que, bajo ciertas condiciones, puede ser objeto de identificación y señalamiento" (Restrepo 2008, p. 200). De otra parte, el racismo latente, no se percibe de modo aparente. Restrepo plantea que "Este racismo está arraigado en el sentido común y se ha naturalizado tanto que trabaja predominantemente desde el inconsciente, de forma soterrada pero eficaz, en los procesos de diferenciación y los ejercicios de exclusión de unas poblaciones o individuos con base en articulaciones raciales que tienden a no aparecer como tales" (Restrepo 2008, p. 200). lo afrodescendiente no es algo que se aprende en sí mismo, es más bien un contenido que se internaliza y se objetiva en la experiencia de hacerse parte de una sociedad determinada.

En 1979, Beryle Banfiel, presidenta del Consejo de Libros Interraciales para los Niños, señalaba algunos asuntos esenciales para comprender las raíces de una actitud racista en la infancia, entre ellos el referido a los manuales escolares y su tratamiento de la historia y la cultura de los pueblos del Tercer Mundo: "...las ilustraciones de los libros refuerzan poderosamente los estereotipos raciales de los textos y desempeñan un papel considerable en la formación de las primeras imágenes que el niño tiene de otros pueblos. Actualmente, esos estereotipos se han internacionalizado. Entre ellos figuran el niño africano desnudo, con una ajorca en el tobillo; el 'indio' mexicano cubierto con un gran sombrero y reclinado junto a un nopal; el indio norteamericano semidesnudo, con un tocado de plumas y armado de arco y flechas; el culí chino; el rubio vaquero norteamericano...."

Se trata, desde luego, de figuras caricaturescas que, como toda caricatura, tienen algo de verdadero y algo de falso. Pero el peligro radica en que la percepción del niño se polariza hacia ellas (Banfield 1979, p. 31).

Retomo esta nota editorial para destacar que Banfiel, y seguramente muchos otros, anticipaba que la internacionalización de estos estereotipos iba a producir en el mediano plazo un discurso multicultural globalizado, objeto de enseñanza y divulgación en los textos y manuales escolares, y cuyo enfoque está sostenido en la representación negativa de las culturas y las poblaciones de la periferia (entiéndase "Tercer Mundo"). Así las cosas, el desenvolvimiento del racismo como un hecho asociado a la historia de la escuela corre a la par con los discursos que se producen y se han producido acerca de la externalidad de lo moderno/occidental.

La escuela como emblema de la institución del saber oficial contiene una dimensión epistémica que opera concretamente a través de los saberes escolares que circulan legítimamente y a diario en las prácticas y los dispositivos de enseñanza, y los cuales básicamente deben entenderse como el saber autorizado para las generaciones más jóvenes².

2 Saberes escolares, conocimientos provenientes del ámbito de las denominadas disciplinas científicas que se seleccionan como objeto de enseñanza para cada una de las áreas del currículo que se imparte en la escuela. Esta organización es jerarquizada y se fundamenta en el estatuto de universalidad y validez epistemológica; por ello, los saberes escolares se constituyen en una expresión concreta del conocimiento oficial. 
Los trabajos realizados en Colombia por las investigadoras María Isabel Mena y Sandra Soler, evidencian que los saberes escolares promovidos a través de los currículos, los textos escolares, los planes de estudio y las prácticas de enseñanza de los maestros producen una invisibilización y/o distorsión en relación con lo afrodescendiente en la historia cultural, política y económica de la nación. En este mismo sentido, los estudios recalcan la presencia de representaciones estereotipadas que circulan en estos materiales de enseñanza, y que en su condición de saberes oficiales, mantienen imágenes fijas y reducidas de la gente negra, palenquera, raizal y/o afrocolombiana ${ }^{3}$. Desde este punto de vista, se reconoce cómo en el terreno de la enseñanza de las ciencias sociales escolares se reproduce un silenciamiento y/o invisibilización de los afrodescendientes y un tratamiento marginal y sesgado respecto a su historia y a la del continente africano (Díaz, 2008).

Soler, a partir de las propuestas de Herrera et al. (2003), plantea que durante los inicios del siglo XX la escuela fue una de las principales generadoras $\mathrm{y}$ transmisoras del discurso racista ${ }^{4}$-y aunque en el terreno de las políticas educativas ese discurso haya desaparecido

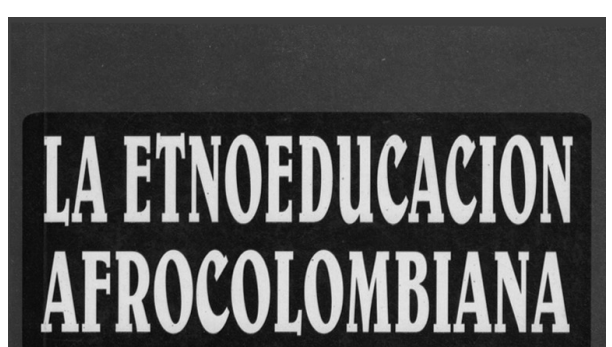

3 El fenómeno de la estereotipación es aquel que asocia la condición racial de las personas, con posiciones, roles y jerarquías sociales fijas e inferiorizadas. Como lo señala Stuart Hall: «Los estereotipos retienen unas cuantas características "sencillas, vívidas, memorables, fácilmente percibidas y ampliamente reconocidas" acerca de una persona, reducen todo acerca de una persona a esos rasgos, los exageran y simplifican y los fijan sin cambio o desarrollo hasta la eternidad... La estereotipación es, en otras palabras, parte del mantenimiento del orden social y simbólico. Establece una frontera simbólica entre lo "normal" y lo "desviante", lo "normal” y lo "patológico", lo "aceptable" y lo "inaceptable", lo que "pertenece" y lo que no pertenece o lo que es "Otro", entre "internos" y "externos", "nosotros y ellos"» (Hall 2010, p. 430).

4 Herrera (2001) señala además, que los debates promovidos por los intelectuales liberales de principios de siglo, en cabeza de figuras como Miguel Jiménez López y Luis López de Mesa, respecto de la eugenesia y la supuesta "degeneración de la raza", fueron definitivos en el terreno de las políticas educativas y en la configuración de un ideal de nación blanco-mestiza. Particularmente se debe recordar que estos personajes tuvieron poder político en el ministerio de gobierno y de educación de la época. nominalmente para darle paso a las ideas sobre "lo multiétnico y pluricultural"- ello no implica la desaparición del racismo, más bien su expresión renovada en el plano discursivo. La autora encuentra que el tratamiento en algunos materiales y textos escolares produce una visibilidad estereotipada de las culturas y las poblaciones negras y/o afrocolombianas, cuyas ilustraciones y fotografías les asocia con situaciones como la pobreza, el crimen, la marginalidad y el folclor. Algunas de las tesis más relevantes que propone Soler (2009) para analizar el fenómeno contemporáneo del discurso racista de los textos escolares se relaciona con un tratamiento que resalta la homogeneización y el etnocentrismo blanco, y explica el problema de la discriminación racial como resultado histórico de la imposición de unas sociedades más poderosas y civilizadas, sobre otras menos desarrolladas e inferiores.

Según el estudio de Mena (2009), los contenidos de algunos textos escolares de ciencias sociales producidos a finales de la década de los años noventa presentan una versión fragmentada acerca de la historia afrodescendiente que, entre otras cosas, desconoce su participación en los procesos independentistas -razón por la cual opera una enseñanza "colonial" de la historia sostenida en prejuicios raciales y versiones eurocéntricas-. "Las Ciencias Sociales y Humanas continúan plagadas de unos relatos profundamente etnocéntricos y eurocentrados que sostienen por esa vía los principales estereotipos urdidos sobre los afrocolombianos desde la época colonial, por un lado que su historia se inicia con la esclavización, por otro, que a pesar de esa circunstancia, viven alegres, danzando y ocupados de las tareas fuertes para las cuales están biológicamente equipados, y en tercer lugar estos imaginarios naturalizan desde el punto de vista cultural, las relaciones construidas desde el mundo colonial" (Mena, 2009, p. 107).

Otra de las aristas del discurso racista de los textos escolares se encuentra en la cartografía producida para la enseñanza de la geografía. Soler (2009) y Jojoa (2008) describen cómo algunos de estos materiales contienen imágenes y definiciones de una geografía cultural y humana de la afrocolombianidad incompleta y que establece vínculos naturales e inmodificables 
entre clima/raza y territorios/culturas. De allí emerge un mapa que reduce lo negro/afrocolombiano al determinismo geográfico decimonónico ${ }^{5}$, para el cual "la región andina, propia de los climas fríos y medios, se erigió como el emblema de la cultura civilizada, en contraposición a las geografías del mar, los ríos y la selva, a las cuales se les asoció con las regiones de la barbarie y del atraso cultural" (Castillo, 2010, p. 77). Esta cartografía refuerza el mantenimiento de estereotipos que atribuyen rasgos acerca del temperamento, las habilidades y las potencialidades de las personas, como resultado de su contexto geográfico de origen:

Con respecto a la ubicación geográfica, los textos escolares establecen una especie de determinismo geográfico cuando vinculan la existencia cultural e histórica de las poblaciones afrocolombianas con su pertenencia a ciertas regiones naturales, a cierto tipo de climas, a cierto tipo de regiones geográficas. Este determinismo lleva a reforzar estereotipos que se han producido a lo largo de nuestra historia social, y que llevan a atribuir a las personas ciertos rasgos en virtud de su origen geográfico, por ejemplo la idea que la gente de tierra fría es muy trabajadora, o que a la gente de tierra caliente le gusta el baile (Jojoa, 2008, p. 76).

A pesar de los resultados socio demográficos producidos por el censo Dane $2005^{6}$-los cuales fueron ampliamente divulgados- en algunos textos escolares de ciencias sociales persiste un tratamiento que invisibiliza la presencia de la población negra y/o afrodescendiente en regiones como los valles interandinos, la Amazonía, la Orinoquía y los grandes núcleos urbanos del país. Como lo reconoce Soler en su análisis de dieciséis textos escolares ${ }^{7}$ :

5 Al respecto Peter Wade se refiere al concepto de geografía cultural o topografía moral. Ver Wade, Peter (2000). Raza y Etnicidad en América Latina. Quito, Ediciones ABYA-YALA. pp. 26-27.

6 Según los datos oficiales (Dane, Colombia Nación Multicultural, 2005), los registros reportan presencia afrocolombiana en la totalidad de las 33 entidades territoriales departamentales. Complementariamente, las cifras del informe del Observatorio de Discriminación Racial de la Universidad de los Andes indican que, en el 2008, el 72\% de la población afrocolombiana, raizal, y/o palenquera se encontraba en centros urbanos; Cali, Medellín y Bogotá se muestran como las ciudades con mayor concentración de esta población. Ver: El derecho a no ser discriminado: primer informe sobre discriminación racial y derechos humanos de la población afrocolombiana (versión resumida) / César Rodríguez Garavito [et al.], Bogotá: Universidad de Los Andes, Facultad de Derecho, CIJUS, Ediciones Uniandes, 2008.

7 El estudio estuvo focalizado en 16 materiales producidos entre los años 2002 y 2004 por dos de las mayores empresas editoriales de textos escolares en Colombia: Grupo Editorial Norma y Editorial Santillana (Soler, 2004, p. 111).
Resulta sorprendente la omisión de la población negra en el Valle del Cauca, Cauca o Nariño, que forman parte de lo que se conoce como la costa pacífica, totalmente olvidada de la geografía y la historia de Colombia. Muchos de los departamentos aparecen con fotografías de la población indígena, pero ninguno presenta fotos de población negra. Esto llevaría a niños y niñas a la errónea idea de que en Colombia sólo existe población negra en el Chocó, dejando de lado el resto de la costa pacífica, mayoritariamente negra. Además, se deja de lado la población negra de la costa atlántica, que aunque no es mayoría, sí constituye una buena parte de la población (Soler, 2004, p. 112).

Este argumento permite inferir una doble invisibilidad para el caso de las poblaciones negras y/o afrocolombianas de los valles interandinos y regiones como la Amazonía y la Orinoquía, por su condición racial y por su localización en regiones que tradicionalmente no se reconocen con presencia afrodescendiente. De otra parte, resulta también la producción de dos tipos de imágenes, una estereotipada que atribuye fijeza territorial a lo "racial" (lo negro/afrodescendiente) y otra de ocultamiento de lo étnico-racial en las denominadas "geografías andinas".

En términos generales, los estudios que he retomado muestran que los textos escolares, vistos como dispositivos de saber, proveen a maestros y estudiantes una visión racista de las poblaciones negras, raizales, afrocolombianas y/o palenqueras representadas en un nivel de inferiorización. Esto se corrobora en el estudio en relación con el racismo en la escuela bogotana, realizado por el equipo de Mena (2010) para el cual se aplicó un instrumento que contenía algunas ilustraciones de textos escolares alusivas a personas afrodescendientes, con la finalidad de que los encuestados opinaran acerca del significado que atribuían a tales ilustraciones. Las respuestas producidas por los docentes participantes permiten demostrar que estas imágenes tomadas de los textos escolares contienen "una iconografía racializada que refuerza los estereotipos que existen sobre las comunidades afrodescendientes" (Proyecto: Dignificación de los afrodescendientes y de su cultura a través de la etnoeducación en Colombia, 2009, p. 108).

Aunque en la última década se han producido algunas "novedades editoriales" que incorporan imágenes y contenidos sobre la afrocolombianidad, Soler (2009) demuestra que esta inclusión mantiene un tratamiento estereotipado:

Las fotos de los afrocolombianos tienden a aparecer relacionadas con pobreza, abandono, desempleo, 
segregación o desplazamiento. Dos fotos se asocian al deporte y en un único caso aparece una foto de una mulata trabajando en un computador; la gente negra no aparece en oficinas o realizando alguna actividad profesional. En los textos de los últimos grados aparecen sólo relacionados con la esclavitud y la discriminación. Lo que enfatiza más el proceso de discriminación contra esta etnia. Cabe resaltar que esto ocurre más en los textos de Santillana que en los de Norma (Soler, 2009, p. 259).

En síntesis, estos trabajos referenciados en este apartado permiten concluir que el fenómeno del racismo en los textos escolares se legitima en las políticas del conocimiento oficial existentes y, por tal razón, se requiere de alternativas epistémicas para contrarrestar sus efectos en la formación de las comunidades educativas. Se trata de un problema sin resolver aún, ni en los debates de la enseñanza de las ciencias sociales en Colombia como tampoco en los planes formativos de las Facultades de Educación o en los planes educativos oficiales. En resumen, mientras en el terreno de las políticas del conocimiento el tratamiento de lo negro y/o afrocolombiano siga siendo estereotipado, el racismo -latente y manifiesto- será contenido de los saberes escolares sobre las ciencias sociales. "Al finalizar el bachillerato los jóvenes desconocen la presencia negra en el mundo y en Colombia. No saben nada con respecto a su cultura, economía y costumbres ni desarrollo sociológico, y seguramente también habrán olvidado la presencia de las comunidades indígenas, que se abandonó años atrás en la primaria" (Soler, 2009, p. 259).

Si bien los estudios de Soler y Mena no tienen por objeto dar cuenta de los procesos de recepción acerca de los contenidos de los textos escolares -es decir, las mediaciones agenciadas por quienes son su audiencia mayoritaria, niños, niñas, jóvenes y maestros- quisiera cerrar este apartado con algunas ideas complementarias. En primer lugar, los discursos racistas circulan a lo largo y ancho de la geografía del sistema educativo colombiano, pues los textos escolares de ciencias sociales se producen para un "mercado nacional" que incluye población mestiza, indígena, afrocolombiana, etc.; en esta medida, podemos aceptar que existe una recepción diferenciada de sus contenidos y, por tanto, unos impactos también diferenciados, según se trate en cada caso. Por ejemplo, para las poblaciones negras y/o afrocolombianas, el efecto del discurso racista de los textos escolares seguramente debe entenderse como endoracismo -es decir, un racismo que se ejerce al interior del mismo grupo racial y que se manifiesta en rasgos como una baja o nula autovaloración de la condición racial y una autonegación de la misma- ${ }^{8}$. Otro aspecto se relaciona con la contingencia de la cultura escolar acerca de este fenómeno del racismo, pues sus rituales más emblemáticos, como las izadas de bandera, los festivales, los reinados y las celebraciones de fiestas $p a-$ trias, constituyen factores que refuerzan, afirman y/o interpelan los estereotipos aquí tratado. Es probable que en este ámbito de la vida escolar encontremos un racismo con mayor anclaje que el descubierto en los análisis de los textos escolares señalados hasta ahora.

Frente a este complejo y dramático panorama, desde finales de la década de los años setenta del siglo XX, algunos intelectuales y movimientos de comunidades negras y/o afrocolombianas han insistido, y continúan haciéndolo, la necesidad de combatir el racismo en el sistema educativo, y por ello han propuesto en distintos momentos, iniciativas de orden jurídico y pedagógico al respecto. Será solo con la reforma constitucional de 1991 y la expedición de la Ley 70 de 1993 para comunidades negras cuando se produzca una respuesta parcial a estas viejas demandas.

En las siguientes páginas se retoman algunas pistas históricas y contextuales para entender el episodio de la escritura pedagógica afrocolombiana como una continuidad en las luchas contra el racismo, iniciadas a mediados del siglo pasado, pero cuya estrategia y táctica se localizan ahora en el campo de los saberes escolares y en la producción de cartillas, manuales y textos escolares creados de puño y letra afrocolombianos.

\section{La impostergable inclusión del estudio de la cultura negra en los pénsumes educativos...}

\section{Manuel Zapata Olivella}

La preocupación por la educación hace parte sustantiva del telón de fondo que acompañó los debates y las luchas políticas de líderes y organizaciones negras y/o afrocolombianas a lo largo del siglo XX. Como lo señalan Castillo y Caicedo (2010), el racismo y la segregación racial son elementos constitutivos de las "primeras intervenciones públicas de las poblaciones negras en relación con la educación”, pues en regiones

8 Al respecto Mosquera señala que el endoracismo «es el resultado de los siglos de explotación esclavista y de enajenación de la personalidad y la identidad cultural africana [...] expresiones degradantes del endoracismo como las siguientes: “¿Uno bien negro para casarse con otro negro?”, “Hay que casarse con blanco para mejorar la raza", "Hay que casarse con blanca para entrar en sociedad", "Hay que arreglar la raza”, "Hay que mejorarla raza”, "Hay que aclarar la raza”, "Hay que arreglar el pelo", “Pelo malo”» (Mosquera, 1999, p. 40). 
como el Chocó, hasta mediados de los años treinta, operaban prácticas de segregación racial. A pesar de las adversidades y la escasa oferta escolar para las zonas rurales del Pacifico, la educación sería vista, con el paso del tiempo, como el camino más eficaz para superar los problemas de pobreza y marginalidad; es decir, como un medio de ascenso social (Villa, 2001). Hacia mediados de esta década hizo presencia en la arena política nacional una generación de políticos negros, de filiación liberal y provenientes en su gran mayoría del Pacifico, quienes tendrían un papel central en la expansión de la escuela en sus regiones, así como en la destinación de apoyos parlamentarios para los estudios universitarios de muchos jóvenes oriundos de estas poblaciones. Fundamentalmente, la figura de Diego Luis Córdoba encarna una postura emblemática respecto de la educación de los chocoanos.

Para la década de los años cincuenta, Colombia experimenta una importante etapa de modernización económica, con lo cual tiene lugar un proceso de expansión educativa a lo largo y ancho del país. Una minoría de la población negra se escolarizó durante estas primeras décadas ${ }^{9}$; este evento derivó en el surgimiento de intelectuales, políticos, maestros, poetas y escritores, cuyas trayectorias se convertirán, con el paso del siglo, en referencia obligada en la literatura, la antropología y la historia colombiana ${ }^{10}$. Esta generación letrada de gente
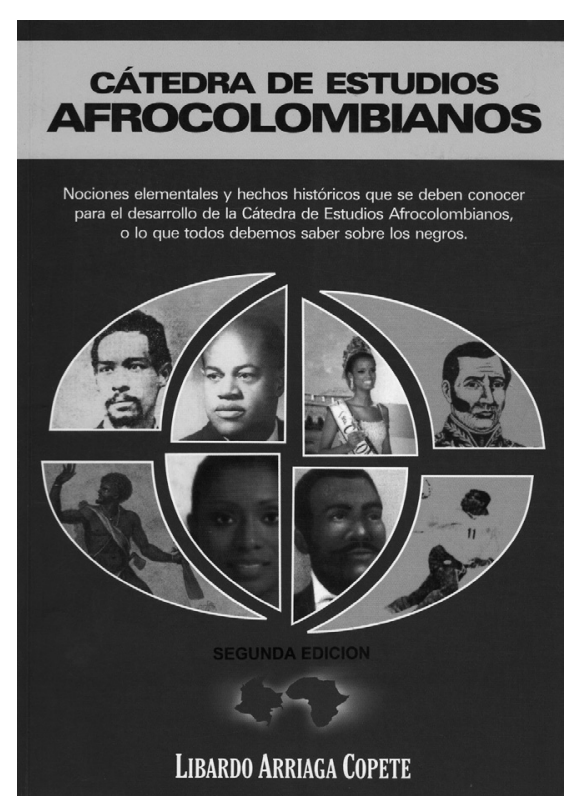

Para mediados de los años setenta vendría un hito fundamental en la historia de los procesos organizativos de las poblaciones negras en Colombia: la realización del Primer Congreso de la Cultura Negra de las Américas, celebrado en Cali en 1977. El encuentro contó con la participación de destacadas figuras de África, América y Europa y su apertura estuvo a cargo de Manuel Zapata Olivella, quien planteará en su discurso inaugural: "en nuestras escuelas y colegios no se enseña la historia del África; la participación creadora del negro en la vida política, económica, cultural, religiosa y artística se soslaya, minimizándola" (1988, p. 19). De manera consecuente, señaló la necesidad de oficializar los estudios de la cultura negra en los siguientes términos: "La delegación colombiana presentará una proposición para que oficialmente se incorpore la enseñanza de la Historia de África en la escuela primaria y secundaria, a la par de que se exija por parte de los profesores un mayor análisis del significado de la presencia negra en nuestra comunidad a través del proceso histórico desde su arribo e integración en la vida económica, social y cultural" (Zapata Olivella, 1988, p. 19-21).

Como lo ha referido Garcés (2008), durante las décadas de los años 70 y 80 del siglo XX, este movimiento de las negritudes se expande por las regiones y plantea "un nuevo discurso y una crítica severa al sistema educativo". En 1986, Sancy Mosquera, director del negra representa el antecedente más relevante respecto del episodio de los textos escolares afrocolombianos, al cual se hará referencia más adelante y que, sin lugar a dudas, dejó sentadas las bases de una escritura afirmada en la condición racial como icono de afirmación y dignificación.

9 Se hace necesario recalcar que en este momento de la historia colombiana los manuales escolares de ciencias sociales fungieron como insumo de una identidad nacional fundamentada en la supuesta supremacía racial (blancoeuropea) y la "inferioridad del indio y el negro" Herrera (2001), así que estos proceso de escolarización tuvieron lugar bajo este paradigma.

10 Solo algunos nombres: Diego Luis Córdoba (1907-1964); Rogerio Velásquez (1908-1965); Jorge Artel (1909-1994); Miguel A. Caicedo (1919-1995); Natanael Díaz (1919-1964); Manuel Zapata Olivella (1920-2004); Arnoldo Palacios (1924); Hugo Salazar Valdés (1926-1977); Delia Zapata Olivella (19262000) y Helcías Martán Góngora (1920-1984).
Centro de Estudios Franz Fanón, propuso, en el marco del Seminario Internacional La participación del negro en la formación de las sociedades latinoamericanas, celebrado en 1986, "el replanteamiento del sistema educativo, incluyendo la historia, el aporte y la presencia del negro en la formación de la vida nacional". De este modo, se retoma la vieja solicitud de cursos referidos a la historia del negro en Colombia como alternativa concreta a su invisibilidad histórica. Posteriormente, el Movimiento Cimarrón, en cabeza de Juan de Dios Mosquera, va a plantear en 1987 una aguda crítica al sistema educativo colombiano y su impacto en los procesos de inferiorización psicológica del negro.

El modelo educativo que existe en las comunidades negras es productor de maestros y es reproductor de la ideología dominante. No es un modelo que nos permita habilitarnos para explotar racionalmente nuestros recursos y desarrollar nuestra identidad, y en este campo de la identidad la educación es re- 
productora de prejuicios raciales, es reproductora de una sicología social que inferioriza y subvalora a las comunidades negras al no reconocerlas como sujetos protagonistas de la historia y de la construcción nacional de estas naciones, sino solamente objetivizarlas como esclavas; ahí empieza y termina la historia de nuestras comunidades. Nosotros, dentro del campo de la educación, estamos reivindicando una nueva historia, estamos reivindicando una nueva concepción geográfica y geopolítica de lo que es la comunidad negra nacional (Mosquera, 1987, p. 17).

En un pronunciamiento hecho en 1988, el Movimiento Nacional Cimarrón reclama para las comunidades negras de Colombia: "El derecho a ejercer y asumir la Identidad Étnica, la Cultura y la Historia Afrocolombiana, en los programas educativos y mediante la fundación y sostenimiento de museos de cultura afrocolombiana, casas de la cultura afrocolombiana, grupos folclóricos y festivales regionales y nacionales de cultura afrocolombiana [...] El derecho a programas de estudios afrocolombianos en las instituciones educativas de las comunidades y en las universidades de la Nación" (Movimiento Nacional Cimarrón, 1988, p. 45).

Estos trazos superficiales esbozados a manera de semblanza histórica, son esenciales para comprender las insistencias de intelectuales y organizaciones negras y/o afrocolombianas en la segunda mitad del siglo XX, respecto de lo que Manuel Zapata Olivella denominó, en 1977, "la impostergable inclusión del estudio de la cultura negra en los pénsumes educativos en aquellos países donde la etnia nacional tenga el aporte africano como una de sus tres más importantes raíces" (Zapata Olivella, 1988, p. 20).

Estas demandas educativas recobran voz propia en la década de años noventa, cuando, como consecuencia de la reforma constitucional de 1991, se promovieron dos grandes propuestas, la competente a la etnoeducación afrocolombiana como una política cultural de las comunidades negras, raizales y palenqueras -orientada fundamentalmente a fortalecer sus procesos identitarios, culturales y comunitarios- y la de implementación de la Cátedra de Estudios Afrocolombianos (CEA), como un mecanismo para erradicar el racismo y la invisibilidad producidos en el sistema educativo nacional ${ }^{11}$. Se trata, entonces,

11 Esta normativa, derivada de la reglamentación de la Ley 70 o de Comunidades Negras de 1993, establece el carácter obligatorio de la CEA en todos los establecimientos educativos de la educación básica y media en Colombia y determina que su ámbito de aplicación opera en el grupo de “áreas obligatorias y fundamentales establecidas en el artículo 23o de la Ley 115 de 1994, correspondiente a Ciencias sociales, historia, geografía, constitución política y democracia" (Decreto 1122, de un trayecto a lo largo de tres décadas en el cual se pueden reconocer los bordes de un pensamiento educativo negro y/o afrocolombiano que hizo parte de la reforma educativa de finales del siglo XX en Colombia, y cuyos efectos de orden político, institucional, cultural, pedagógico y organizativo constituyen un vasto campo de procesos que incluyen desde la formación de etnoeducadores hasta las demandas contemporáneas por una educación propia y, por tanto, no pueden leerse como hechos puntuales.

\section{Manuales de puño y letra afrocolombiana}

Quiero hacer un "salto de página" para focalizar la mirada en el asunto del surgimiento de una escritura pedagógica afrocolombiana para entender la emergencia de un género de texto escolar producido para la enseñanza un nuevo saber escolar: el de la historia y la cultura afrocolombiana y en el entendido de que este dispositivo de saber constituye un mecanismo de lucha epistémica contra el racismo y la invisibilidad. Este proceso se encuentra plenamente articulado con los hechos históricos reseñados en este apartado, y en esa medida retoman la reclamación de incluir lo negro y/o afrocolombiano en el terreno de las políticas del conocimiento.

El balance producido por el Proyecto MANES ${ }^{12}$ en 2001 señala que en nuestro continente los sistemas escolares cumplieron un papel estratégico en los procesos de integración nacional, y por tanto el interés de los investigadores respecto a los textos y manuales escolares se ha concentrado en rastrear este fenómeno: “...en América Latina la gran mayoría de los trabajos sobre libros escolares que se han realizado desde la Historia de la Educación han abordado prioritariamente su influencia en la creación de las identidades nacionales y los imaginarios colectivos, así como en los procesos de secularización de los diversos países a partir de la Independencia" (Ossenbach y Somoza, 2001, p. 26).

Artículo 2º․ Igualmente en 2001, el Ministerio de Educación Nacional publica un documento de lineamientos curriculares para la CEA, el cual es resultado del trabajo de un equipo de líderes afrocolombianos, quienes diseñan una propuesta conceptual y pedagógica para este nuevo campo del saber escolar (Ministerio de Educación Nacional, Decreto 1122 de 1998. Serie Lineamientos Curriculares. Cátedra de Estudios Afrocolombianos).

12 Hoy establecido como Centro de Investigación MANES tiene como objetivo principal la investigación de los manuales escolares producidos en España, Portugal y América Latina durante los siglos XIX y XX, y opera como una gran red de universidades y grupos de expertos de México, Brasil, Colombia, Argentina, Chile y Venezuela. 
Quiero valerme de la autoridad académica de este planteamiento y sus autores para iniciar este apartado con una declaración obligada. Este primer plano de reconocimiento que propondré para los manuales producidos por autores afrocolombianos se sitúa en el entendido que este tipo de materiales responde a unos modos de producción y uso no oficiales y, por tanto, requieren otros referentes de análisis, seguramente distintos y/o complementarios a los que se han aplicado para el caso de los textos escolares inscritos en las políticas del conocimiento oficial. De este modo, voy a proponer un plano descriptivo de los textos en cuestión respecto de tres aspectos: quién escribe (el autor), qué dice y desde dónde lo dice (locus de enunciación) y para qué lo dice (intencionalidad comunicativa). A sabiendas de que nos enfrentamos a una amplísima existencia de materiales escritos que cumplen con las características estructurales y funcionales de lo que reconocemos hoy como textos escolares para la enseñanza de lo afrocolombiano, me voy a concentrar en dos manuales para docentes, producidos por intelectuales afrocolombianos durante el período de 1999-2004 y cuya difusión al interior del magisterio ha sido significativa para los procesos de formación en el terreno de la Etnoeducación.

Afrocolombiana y de implementación de la Cátedra de Estudios Afrocolombianos, respectivamente. Las obras escogidas son apenas una muestra de la amplia y heterogénea producción escrita que ha corrido en los últimos años en esta materia, de ahí la decisión de abordar dos de las obra fundantes de este nuevo ámbito de los manuales para docentes.

Juan de Dios Mosquera, dirigente e intelectual, referenciado anteriormente, es ampliamente conocido por su trayectoria como fundador del Círculo de Estudios Afrocolombianos SOWETO (1976) y del Movimiento CIMARRON (1982). Sus posturas respecto del tratamiento político de lo afrocolombiano se han enmarcado en lo que él mismo denomina Cimarronismo Contemporáneo. Luego de haber escrito dos obras referidas al tema de comunidades negras y la recién promulgada Ley 70 , en enero de 1999, sale a la luz pública su manual para docentes titulado La Etnoeducación Afrocolombiana. Guía para docentes, líderes y comunidades educativas ${ }^{13}$. Se trata, principalmente, de un manual que retoma un rasgo esencial de la época en que surgió el discurso etnoeducativo: su carácter comunitario

13 Esta publicación transitó durante el período de formulación del Decreto 1122 de 1998, reglamentario de la Cátedra de Estudios Afrocolombianos. Por esta razón se explica que el libro en mención no hace ningún tratamiento al respecto de este nuevo elemento normativo para la educación colombiana. y organizativo ${ }^{14}$; con seguridad ello explica que la obra vaya dirigida a quienes cumplen la función etnoeducadora primordial: los maestros, los líderes y las comunidades. En ese sentido, Mosquera escribe para los etnoeducadores o las comunidades etnoeducativas potenciales.

En las doscientas treinta y ocho páginas que constituyen el corpus de este manual se desarrolla un argumento fundamental: la necesidad de implementar la Etnoeducación Afrocolombiana como una forma de superar el racismo estructural del país. Mediante el uso de los mecanismos jurídicos derivados de la reforma Constitucional, pero a la vez retrotrayendo las normas internacionales obtenidas en anteriores períodos de luchas contra el racismo y por lo derechos civiles de las comunidades negras, el autor defiende el planteamiento según el cual la Etnoeducación Afrocolombiana debe ser entendida como un derecho de las comunidades (étnicas) y como "el proceso de socialización y enseñanza a todos los colombianos de la Afrocolombianidad a través de los sistemas educativo, cultural y medios de comunicación" (Mosquera, 1999, p. 25). De esta manera, se introduce la idea de la enseñabilidad de lo afrocolombiano, y para ello manuales como el reseñando serán piedras angulares en su configuración como un hecho posible en el campo pedagógico colombiano, más allá de su promulgación normativa.

Esta obra de Juan de Dios Mosquera está estructurada a nivel temático en seis grandes secciones: la primera comprende una sustentación de orden conceptual y jurídico acerca de la Etnoeducación Afrocolombiana y que transita por una extensión de setenta páginas; una segunda, referida al tema de la Introducción de la Afrocolombianidad en las asignaturas, donde sin contar aún con el decreto 1122 de 1998, Mosquera bosqueja la propuesta de introducir de la Afrocolombianidad "en los Proyectos Educativos Institucionales y en cada asignatura escolar" (Mosquera, 1999, p. 73); una tercera, titulada "Por una nueva Ética Ciudadana frente a la comunidad afrocolombiana", argumenta a lo largo de diez páginas la importancia de asumir el compromiso constitucional respecto de la diversidad étnica como una opción para encontrar salida a los problemas de convivencia que enfrenta la nación colombiana; la cuarta, aborda

14 Podemos reconocer que en los orígenes, la etnoeducación como propuesta emergente de los movimientos indígena y afrocolombiano, se sostenía en una concepción comentarista, según la cual, los procesos (etnoeducativos) hacían parte de la vida integral de las culturas, y en ese sentido, la escuela era sólo uno de los posibles escenarios para su implementación. Con el paso de las reformas y la normatividad, el concepto se localizó en la noción de servicio, y con ello quedó reducida en muchos casos al ámbito de lo escolar (Castillo, 2008). 
el problema del racismo y la discriminación racial en sus distintas expresiones en la vida colombiana y presentan una serie de recomendaciones para lograr la eliminación de este fenómeno -este apartado que consta de veinte páginas, dedica una parte de éstas a analizar el fenómeno del racismo en los libros infantiles y juveniles, lo cual es una verdadera novedad en un manual para docentes-; una quinta, corresponde al tratamiento del tema de las "Raíces de la Identidad Política del Pueblo Afrocolombiano", en la cual se presentan cinco biografías: Benkos Bioho, Diego Luis Córdoba, Nelson Mandela, Martín Luther King y Malcom X; y la sexta, se ocupa de lo referido a los "Logros normativos para la Etnoeducación" y en tres apartados revisa los compromisos jurídicos obtenidos en materia de lucha contra el racismo y la discriminación racial, los obstáculos que debe enfrentar el país en esta materia y finalmente una serie de recomendaciones al respecto -en las últimas 37 páginas el texto presenta tres anexos, uno que incluye el Decreto 804 de 1994 y otros dos correspondientes al Decreto 2249 de 1995 que reglamenta la Conformación de la Comisión Pedagógica Nacional de Comunidades Negras-.

A lo largo de la obra, Mosquera expone las tesis jurídicas y pedagógicas que soportan el ámbito de la Etnoeducación Afrocolombiana, hace uso de un lenguaje hasta entonces prácticamente desconocido para el magisterio colombiano: el de la etnoeducación afrocolombiana. Por ello, seguramente, una buena parte del texto se ocupa de explicar y sustentar la importancia de este nuevo enfoque educativo y sus bondades para el sistema colombiano. En una gramática de los derechos y los compromisos jurídicos, Mosquera le presenta a los docentes una lección básica, la etnoeducación es un asunto nacional, no sólo de la afrocolombianidad, por esta razón planteaba: "Debemos asumir y desarrollar la etnoeducación como un movimiento pedagógico nacional de construcción de una nueva actitud ética de los colombianos en sus pensamientos, relaciones y comportamientos con las Comunidades Afrocolombianas" (1999, p. 26).

Uno de los elementos más sobresalientes de este manual es el referido a las acciones comunitarias que Mosquera propone para lograr la implementación de la Etnoeducación Afrocolombiana y que, sustentadas en el cuerpo normativo existente para entonces, se localiza al menos en tres niveles: el de la gestión cultural, el de la comunicación participativa y el de la participación ciudadana. En total se trata de once propuestas que incluyen, entre muchas otras cosas: “2. Hacer cumplir el decreto 804 de 1994 y la Ley General de Educación, sobre el proceso de concertación de la comunidad con las autoridades para la selección y nombramiento de los educadores, quienes deben pertenecer a la comunidad y ser conocedores ${ }^{15}$ de la Afrocolombianidad y la cultura local" (Mosquera, 1999, p. 69).

En el año 2002, Libardo Arriaga Copete, destacado abogado, historiador y líder chocoano radicado en Bogotá, pone en el escenario de los textos escolares su manual para docentes: Cátedra de Estudios Afrocolombianos. Nociones elementales y hechos históricos que se deben conocer para el desarrollo de la Cátedra de Estudios Afrocolombianos, o lo que todos debemos saber sobre los negros. En la obra, cuya extensión es de 347 páginas y cuyo prologo fue escrito por el maestro Manuel Zapata Olivella, el autor en la introducción plantea: "El presente trabajo busca exponer en forma clara y lo más didácticamente que ha sido posible, cuál es la circunstancia del negro en Colombia a partir de la trata, su asentamiento y su participación en la empresa colonizadora y en los movimientos de resistencia, de qué manera participó en la gesta libertadora, y cuál ha sido su contribución sociocultural a la formación de la nacionalidad colombiana" (2002, p. 17).

A lo largo de once apartados, Arriaga Copete ilustra a sus lectores acerca de aspectos antropológicos, históricos, literarios, geográficos y políticos contenidos en una larga duración afrodescendiente que se remonta desde el siglo sexto hasta nuestros días. Interesado en lograr que su libro sirviera para que los maestros inicien "a los escolares en el conocimiento elemental de una de nuestras raíces, la que había permanecido oculta, o sea la etnia negra" (2002, p. 17), el autor estructura un plan temático que organiza en dos grandes secciones: la primera, "Aportes del Negro a la Identidad Nacional", consta de 200 páginas y diez capítulos que desarrollan un amplio marco de análisis nutrido de la historia y la antropología fundamentalmente; la segunda, "Participación del Negro en la Historia Nacional", comprende una extensión de 142 páginas y un gran apartado que subtitula "El Negro en la Historia Nacional", cuya estructura comporta tres partes correspondientes a los siguientes períodos: Descubrimiento, Conquista y Colonia; Independencia, y comienzo de la República.

El manual está diseñado a manera de lecciones magistrales que oscilan entre quince 15 y 25 páginas, en las cuales se expone la esencia del tema en cuestión, con notas aclaratorias, definiciones claves y datos estadísticos en algunos casos. Además, cada unidad temática cuenta con lecturas complementarias provenientes de expertos en las diferentes áreas y

15 Las itálicas son mías 
que funcionan como aportes del saber experto a lo dicho por el autor ${ }^{16}$.

Un elemento fundamental de resaltar en esta obra consiste en la inclusión de 29 reseñas biográficas de próceres de la independencia ${ }^{17}$ : poetas, políticos, intelectuales y artistas negros y/o afrocolombianos pertenecientes a un período que va desde finales del siglo XIX hasta nuestros días. Además, expone una lista de más de cien hombres y mujeres afrocolombianos destacados en todos los planos de la vida cultural, económica, social y política de la Colombia actual. El valor de este abordaje está en que Libardo Arriaga provee los insumos para una memoria $\operatorname{larga}^{18}$ de lo negro y/o afrocolombiano, al propiciar articulaciones con la historia, juntando piezas, en este caso biográficas, para destacar la presencia negra y/o afrocolombiana en la larga duración con hechos y acontecimientos ejemplares y sobresalientes que estuvieron ensombrecidos por los relatos de la historia oficial.

En ese sentido, el manual para docentes referido aporta un elemento central para resolver lo que Claudia Mosquera (2007) ha denominado la necesidad de "un gran relato compartido" que permita articular en el tiempo y en el espacio de la larga duración la existencia afrodescendiente en Colombia y dé lugar a las memorias diferenciadas, en el sentido de establecer continuidades vinculantes de lo negro, afrocolombiano, raizal y/o palenquero: "Hay que crear un gran relato compartido que conecte todas las maneras de ser negro, afrocolombiano o raizal que existan en el país" (Mosquera, 2007, p. 242). De este modo, Arriaga logra, a lo largo de su texto, argumentar y detallar algunos aspectos ocultados $y / o$ negados en la historia oficial del negro en Colombia. De otra parte, retoma fielmente los objetivos políticos, epistémicos y culturales propuestos en los orígenes de la CEA, los cuales se plantearon como una lucha

16 Gabriel García Márquez, Peter Wade, Alberto Angulo, Nina S. de Fridemman, Aquiles Escalante, Ildefonso Gutiérrez Azopardo, Pedro N'dong Ondo, Manuel Zapata Olivella, José Marcial Ramos, Jaime Arocha y Germán Arciniegas.

17 En este caso incorpora los nombres de militares de Venezuela y el Caribe como Sucre, Infante, Páez, Piar y Petión.

18 El concepto lo retomo de Silvia Rivera Cusicanqui, quien plantea en sus trabajos sobre historia y memoria de las luchas indígenas, una reconstrucción de la larga duración de sus resistencias y rebeliones, para lograr visibilidades y reconocimientos, hasta ahora ocultos (Rivera, 1998, p. 17). desde el sistema educativo contra la invisibilidad y el racismo. En su manual, el autor chocoano define una estrategia concreta para alcanzar estos ideales, ilustrar a los docentes respecto de un saber para el cual no han sido preparados en las facultades o escuelas normales de donde provienen, pero sobre el cual no existe todavía una política de conocimiento oficial definitiva; es decir, que aún su delimitación es transitoria pues se encuentra en construcción ${ }^{19}$.

De los dos manuales presentados en esta sección del artículo, quiero resaltar su escritura pedagógica que ausculta y descubre memorias refundidas y que, desde una gramática de lo afrocolombiano, resuelve lo que Caicedo (2009) ha señalado como la invisibilidad histórica resultante de la gramática de la "historia escrita". Por ejemplo, los escritos biográficos son fundamentales, en la medida que incorporan a la textualidad de la ideas la dimensión vivencial y experiencial de los recuerdos y testimonios que evocan estos personajes.

Se trata de una escritura pedagógica afrocolombiana que debe entenderse como tal, puesto que lo trasmitido se constituye en expresión del qué, del cómo y del quién enseña. En otras palabras, se convierte en una escritura que deja entrever la postura del autor, en este caso afrocolombiano, respecto del saber y de la práctica de este "nuevo" saber pedagógico. "La memoria depositada en los textos escolares puede ser entendida hoy como una paideia, como expresión de un ethos pedagógico-social y como testimonio de un modo de producción didáctica; en definitiva, como la objetivación cultural de un curriculum en todas sus dimensiones, es decir, en sus estructuras y contenidos, en sus imágenes sociales y en sus formas de desarrollo" (Escolano, 2001, p. 39).

El texto o el manual para docentes implica, entonces, una postura de los autores afrocolombianos

$19 \mathrm{Al}$ respecto debe mencionarse que en lo que lleva de promulgada la norma, se han producido dos tipos de materiales por parte del Ministerio de Educación Nacional. Uno derivado del trabajo de la Comisión Pedagógica Nacional y algunos asesores convocados por ésta, cuya publicación se hizo en el año 2000, en el marco de la Serie Lineamientos Curriculares, con las que se actualizó al conjunto del magisterio nacional en este ámbito de las políticas oficiales del conocimiento escolar. El segundo, producido por un equipo de la Universidad del Cauca, bajo la coordinación de Axel Rojas, en el año 2008, en el cual tuve la oportunidad de participar como escritora de algunos apartados. Para el momento que Arriaga produce su obra, sólo circula el primero de tales documentos. 
respecto de la necesidad de una pedagogía que produzca afroreparaciones; es decir, capaz de hacer notar los silencios, las ausencias y las negaciones que han prevalecido en el modo de presentar y representar lo negro y/o afrocolombiano y, a la vez, con la suficiencia para dignificarlo por sus propios méritos. En esa medida, tanto Mosquera como Arriaga representan y constituyen la voz de un "nos" racializado y etnizado que orienta las prácticas de enseñanza, sus contenidos y sus fronteras. Por ello, la escogencia de autores, disciplinas y biografías responden a un plano de la ideología y no sólo de la generalidad de lo negro y/o afrocolombiano. La intención consiste en resaltar aquello que a los ojos de uno y otro escritor es memorable, digno de constituirse en "lección", en contenido curricular, si se quiere. Por ello, estos manuales, así como los muchos más que se han producido con este mismo sentido, estarían mostrando "las ideologías de sus redactores y aún las que estos atribuyen de forma anticipada e implícita a los sujetos que los han de leer y estudiar" (Escolano, 2001, p. 41).

Los manuales producidos por Mosquera y Arriaga están en la dirección de lo que Mena ha señalado como el ingreso de las Áfricas Posibles a los contenidos y discursos de los textos escolares, como una posibilidad de lograr que "tanto en sus contenidos discursivos como en su iconografía permitirían alojar en los imaginarios de los estudiantes un discurso sobre África y sus diásporas más positivo de lo que se sostiene en los manuales que circulan en las escuelas colombianas" (Mena, 2009, p. 107).

La historia como el saber oficial primogénito se enfrenta a las disputas del conocimiento que le plantean estos textos acerca de la afrocolombianidad. La autoridad académica de sus autores proviene de la "externalidad" de lo que ha sido tradicionalmente el mundo de la pedagogía académica; es decir, se aleja de los centros especializados en educación (llámense facultades o institutos) y se localiza en el lugar de los sujetos que saben lo que el saber oficial ha silenciado. Es muy valioso encontrar en los dos manuales las referencias de expertos de las disciplinas que se han ocupado del estudio de lo negro y/o afrocolombiano, cuyas ideas y hallazgos adquieren funcionalidad para este nuevo saber escolar. De este modo, los aportes, por ejemplo, de grandes figuras de la historia académica como Germán Colmenares o de la antropología, como Nina S. de Fridemman, se "usan" para soportar la legitimidad de lo expuesto.

En el plano pedagógico, estas obras logran articular dinámicas de autoreconocimiento en el aquí y el ahora de las afrodescendencias, en las historias locales, en las memorias colectivas, en las estéticas adaptativas, en esos innumerables modos como las afrocolombianidades se han inventado y reinventado a lo largo de los siglos, manifiestas por ejemplo en la tradición oral, pero sobre todo en las propias biografías de sus hombres y mujeres. Elementos centrales de estos manuales son las iconografías de la memoria larga, como propongo denominar la exaltación de los rostros de negros y/o afrocolombianos con nombre y apellido, históricamente memorables y cuyas imágenes, en justa razón, adquieren un lugar central en los discursos de los textos.

De este modo, estos manuales, así como las cartillas y libros de texto que se han producido en la misma dirección ${ }^{20}$, contribuyen a hilvanar los retazos dispersos y acaso extraviados, de esa memoria larga

20 Me refiero a la magnífica experiencia de producción de cartillas y textos escolares hechos de "puño y letra" por maestros y maestras afrocolombianos, iniciada un poco más de diez años, en regiones como el Pacifico Sur, en el Norte del Cauca, en Palenque de San Basilio, en el Uraba Antioqueño, en Choco, Sur del Valle, Bogotá y Medellín, sólo por mencionar las que conozco de modo personal y directo, pues seguramente es muchísimo más grande su espectro de existencia.

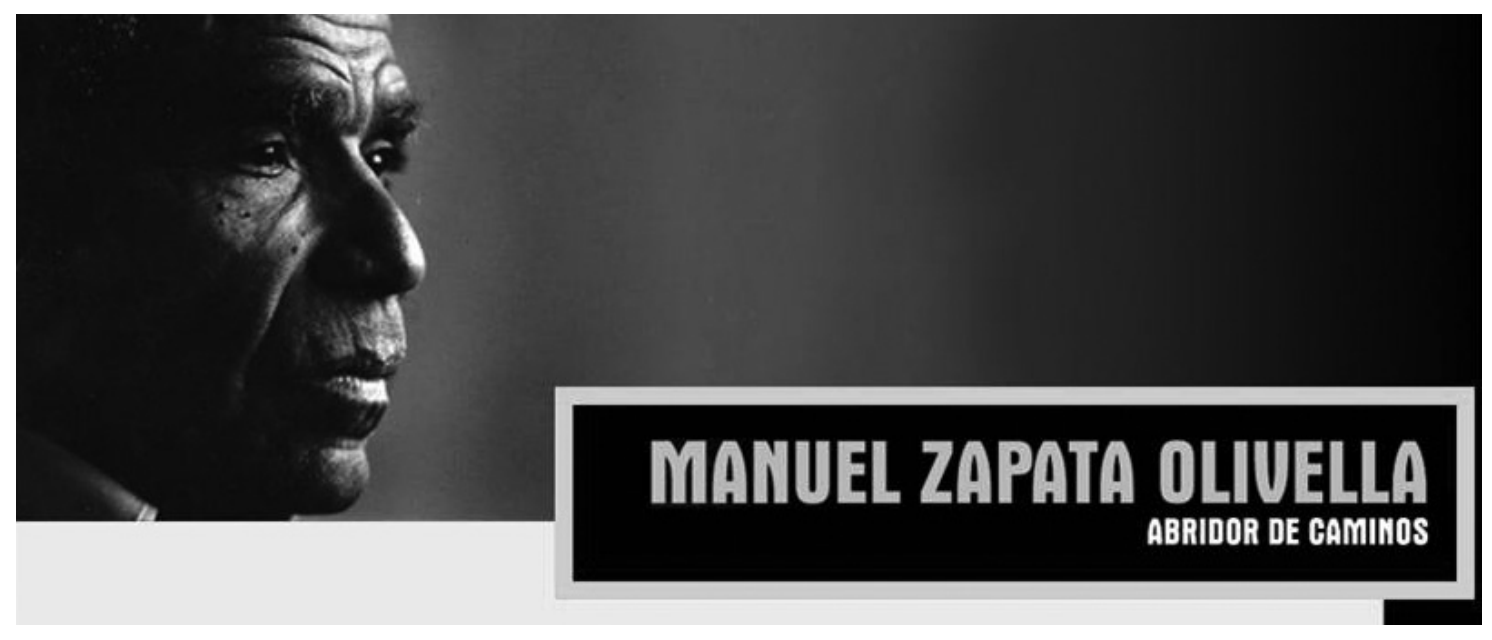


de lo afrodescendiente que ahora aparecen zurcidos para la gala de un relato escrito "raza adentro". Por esta razón, quiero cerrar con la frase enunciativa de la primera página, pues considero que cada manual y texto escolar que se produce y se ha producido de puño y letra negra y/o afrocolombiana sirve de motivo para afirmar, "que la letra con raza, entra". En otras palabras, es posible desde estas gramáticas de la negritud, la negridad, y/o la afrocolombianidad afectar los dispositivos del discurso racista y poner a circular en el sistema escolar colombiano un relato dignificador de su historia. En ese sentido, cada manual, cada cartilla y cada texto que se edita en las grandes editoriales o en los proyectos locales etnoeducativos constituye un hecho concreto de

\section{Bibliografía}

Arriaga Copete, L. (2006), Cátedra de Estudios Afrocolombianos. Segunda Lección. Los negros, ciento cincuenta años después de la abolición de la esclavitud en Colombia, vol. I, Casa Nacional de la Cultura Afrocolombiana, Fondo de publicaciones Afrocolombianas, Bogotá Colombia, RC Publicaciones Ltda.

(2002), Cátedra de Estudios Afrocolombianos. Nociones elementales y hechos históricos que se deben conocer para el desarrollo de la Cátedra de Estudios Afrocolombianos, o lo que todos debemos saber sobre los negros, Colombia, Igasa, Ingenieros Gráficos Andinos S.A.

Banfiel, B. (1979), Raíces tempranas de la actitud racista, en: Correo de la Unesco, Los niños y las imágenes del Mundo, París, UNESCO, p. 31.

Caicedo Ortiz, J. A. (2009), Historia oral como opción política y memoria política como posibilidad histórica para la visibilización étnica por otra escuela, en: Revista Educación y Pedagogía, Facultad de Educación, Universidad de Antioquia, Medellín, núm. 52, pp. 27-42.

Caicedo, M. A. (1992), Sólidos pilares de le educación chocoan, Medellín, Editorial Lealón.

Castillo, G. E. (2010), Del racismo y la discriminación racial en la escuela colombiana, en: Mena, M. I. (coord.), Si no hay racismo no hay Cátedra de Estudios Afrocolombianos, Bogotá, Proyecto Dignificación de los y las afrodescendientes y de su cultura en Colombia, pp. 75-80.

Castillo Guzmán, E. y Caicedo Ortiz J. A. (2010), Las luchas por otras educaciones en el bicentenario: de la iglesiadocente a las educaciones étnicas, en: Revista Nómadas, Universidad Central, Instituto de Estudios Sociales Contemporáneos-IESCO, Bogotá, núm. 33, pp.109-129. afroreparación epistémica, porque hace posible que niños, jóvenes y maestros se encuentren con una narrativa que exalta y da valor al trasegar de los afrodescendientes en nuestro país y en el mundo y con ello producen importantes alteraciones en el orden de las subjetividades, que es donde el racismo -como hecho antiguo- ha causado los mayores estragos.

Agradezco a los escritores y las escritoras de estos nuevos textos escolares haberme brindado con sus trabajos una enorme inspiración para realizar este ejercicio, que es una manera sencilla de reconocer su maravilloso y seguramente solitario esfuerzo, y la gran contribución que ofrecen al campo de la educación colombiana y, especialmente, al ámbito de la etnoeducación afrocolombiana.

Díaz, R. A. (julio-septiembre, 2008), La población afrocolombiana y su lugar en la historia de Colombia: una lectura desde la diáspora africana y la esclavitud, en: Boletín de Historia y Antigüedades, Bogotá, vol. 95, núm. 842, pp. 467-477.

Escolano Benito, A. (2001), El libro escolar como espacio de memoria, en: Ossenbach G. y Somoza M. Los Manuales Escolares como fuente para la Historia de la Educación en América Latina, Madrid, Ediciones UNED, pp. 35-46.

Ossenbach, G. y Somoza M. (2001), Introducción. En: Ossenbach G. y Somoza M. Los Manuales Escolares como fuente para la Historia de la Educación en América Latina, Madrid, Ediciones UNED, pp. 13-34.

Garcés Aragón, D. (2008), La etnoeducación afrocolombiana. Escenarios históricosy etnoeducativos, 1975-2000, Cali, Editorial Valformas LTDA.

Hall, S. (2010), El espectáculo del otro, en: Restrepo, E.; Walsh, C. y Vich, V. (ed.), Stuart Hall Sin Garantías. Trayectorias y problemáticas en estudios culturales, Bogotá, Envión Editores, pp. 419-446.

Herrera, M. C. (2001), Debates sobre raza, nación y educación: ¿hacia la construcción de un "hombre nacional”?, en: Herrera, M. C. y Díaz C. J. (comp.), Educación y Cultura política: una mirada multidisciplinaria, Bogotá, Plaza \& Janés Editores, pp. 117-143.

Herrera, M. C., Pinilla, A.y Suaza, L. M. (2003), La identidad nacional en los textos escolares de ciencias sociales. Colombia 1900-1950, Bogotá, Editorial Universidad Pedagógica Nacional.

Jojoa, Y. (2008), Los textos escolares y las prácticas educativas de los maestros, en: Rojas, A. (coord.), Cátedra de Estudios Afrocolombianos, Aportes para Maestros, Popayán, Universidad del Cauca, pp. 70-80. 
Mena, M. I. (2009), La ilustración de las personas afrocolombianas en los textos escolares para enseñar historia, en: Revista de Historia del Caribe, Barranquilla, Universidad del Atlántico, núm. 15, pp. 105-122.

(2006), La historia de las personas afrocolombianas a partir de las ilustraciones contenidas en los textos de Ciencias Sociales para la Educación Básica, en: Revista Enunciación, Bogotá, Universidad Distrital Francisco José de Caldas, núm. 11, pp. 46-58.

Ministerio de Educación Nacional (1998), Decreto 1122, Reglamentario de la Cátedra de Estudios Afrocolombianos. Bogotá, Imprenta Nacional.

(2001), Cátedra de Estudios Afrocolombianos. Serie Lineamientos Curriculares. Bogotá, Enlace Editores.

Mosquera, J. de D. (1987), El Renacer Cimarrón, en: Revista Solidaridad. Aportes Cristianos para la Liberación. Bogotá, Ediciones Solidaridad, Año IX, núm. 88, pp. 15- 18.

(1999), La Etnoeducación Afrocolombiana. Guía para docentes, líderes y comunidades Educativas, Bogotá, Colombia: Docentes Editores.

Movimiento Nacional CIMARRÓN (1988), Comunidad Negra Colombiana, en: Revista Debate. Al servicio de la Convergencia. Bogotá, sin editorial registrada, núm. 16, pp. 45-46.

Restrepo, E. (2008), Racismo y discriminación, en: Rojas, A. (coord.) Cátedra de Estudios Afrocolombianos. Aportes para Maestros, Popayán, Editorial Universidad del Cauca, pp. 192-204.

Rivera Cusicanqui, S. (2010), Ch'ixinakax utxiwa. Una reflexión sobre prácticas y discursos descolonizadores, Buenos Aires, Ediciones Tinta Limón y Retazos.

Rivera Cusicanqui, S. (1998), Oprimidos pero no vencidos. Luchas del campesinado aymara y quechwa 1900-1980, La Paz, Ediciones Yachaywasi.
Rodríguez, C. et al. (2008), El derecho a no ser discriminado: primer informe sobre discriminación racial y derechos humanos de la población afrocolombiana (versión resumida), Universidad de Los Andes, Facultad de Derecho, CIJUS, Bogotá, Ediciones Uniandes.

Soler Castillo, S. (2004), La escuela y sus discursos. Los textos escolares como instrumentos de exclusión y segregación, en: Revista Sociedad y Discurso, Departamento de Lengua y Cultura de la Universidad de Aalborg, disponible en: www.discurso.aau.dk, núm. 15 , pp. 107-124.

Soler Castillo, S. (2009), Racismo y discurso en los textos escolares: representación de la diversidad étnica y racial en los textos de ciencias sociales en Colombia, en: Arocha, J. (ed.), Nina, Cronista de Resistencias y Disidencias, Bogotá, Centro de Estudios Sociales, Facultad de Ciencias Humanas, Universidad Nacional de Colombia, serie Estudios Afrocolombianos, pp. 233-265.

Villa, W. (2001), La sociedad negra del Chocó: identidad y movimientos sociales, en: Pardo, M. (ed.), Acción colectiva, Estado y Etnicidad en el Pacífico colombiano, Bogotá, Colciencias e ICANH.

Wade, P. (1993), El movimiento negro en Colombia, en: Revista América Negra 5, Bogotá, Pontificia Universidad Javeriana, pp. 118-132.

Zapata Olivella, M. (1998), El congreso de la cultura negra. Nueva era para la identidad de América. Discurso de apertura, en: Primer congreso de la cultura negra de las Américas, Cali, Fundación Colombiana de Investigaciones Folclóricas UNESCO, pp. 19-21. 


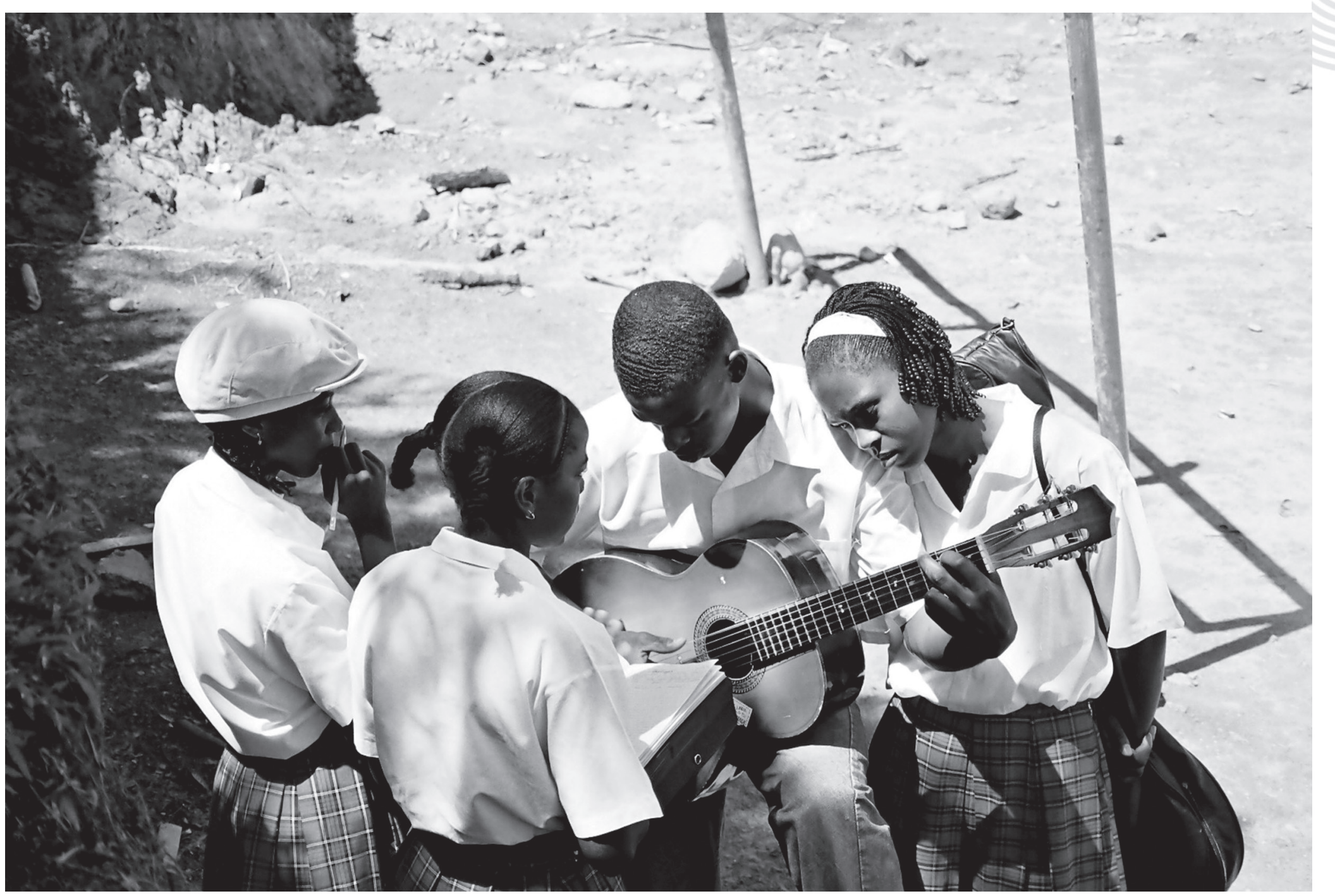

Fotografía. Centro de Memorias Étnicas de la Universidad del Cauca 


\section{Ponencia}

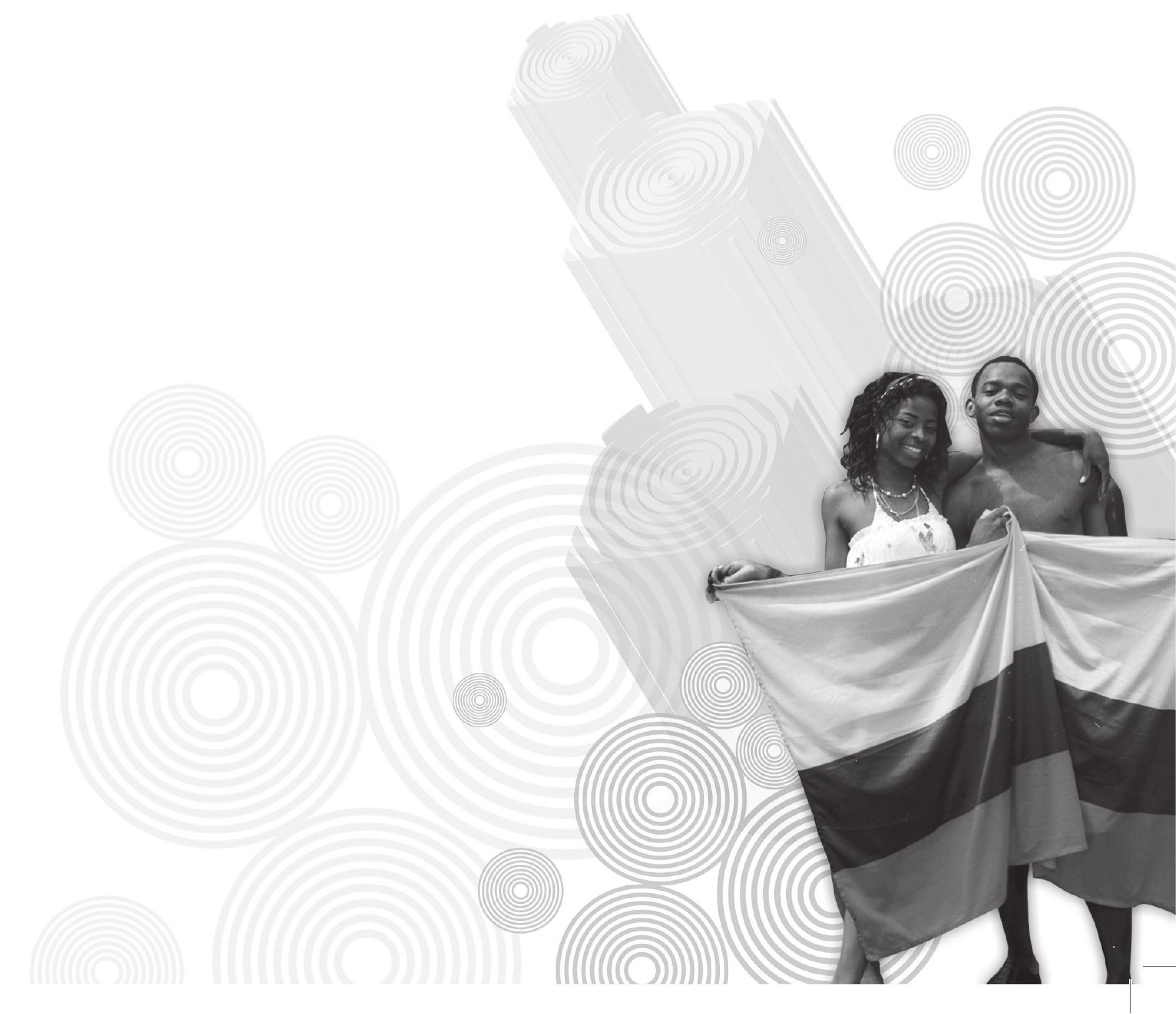




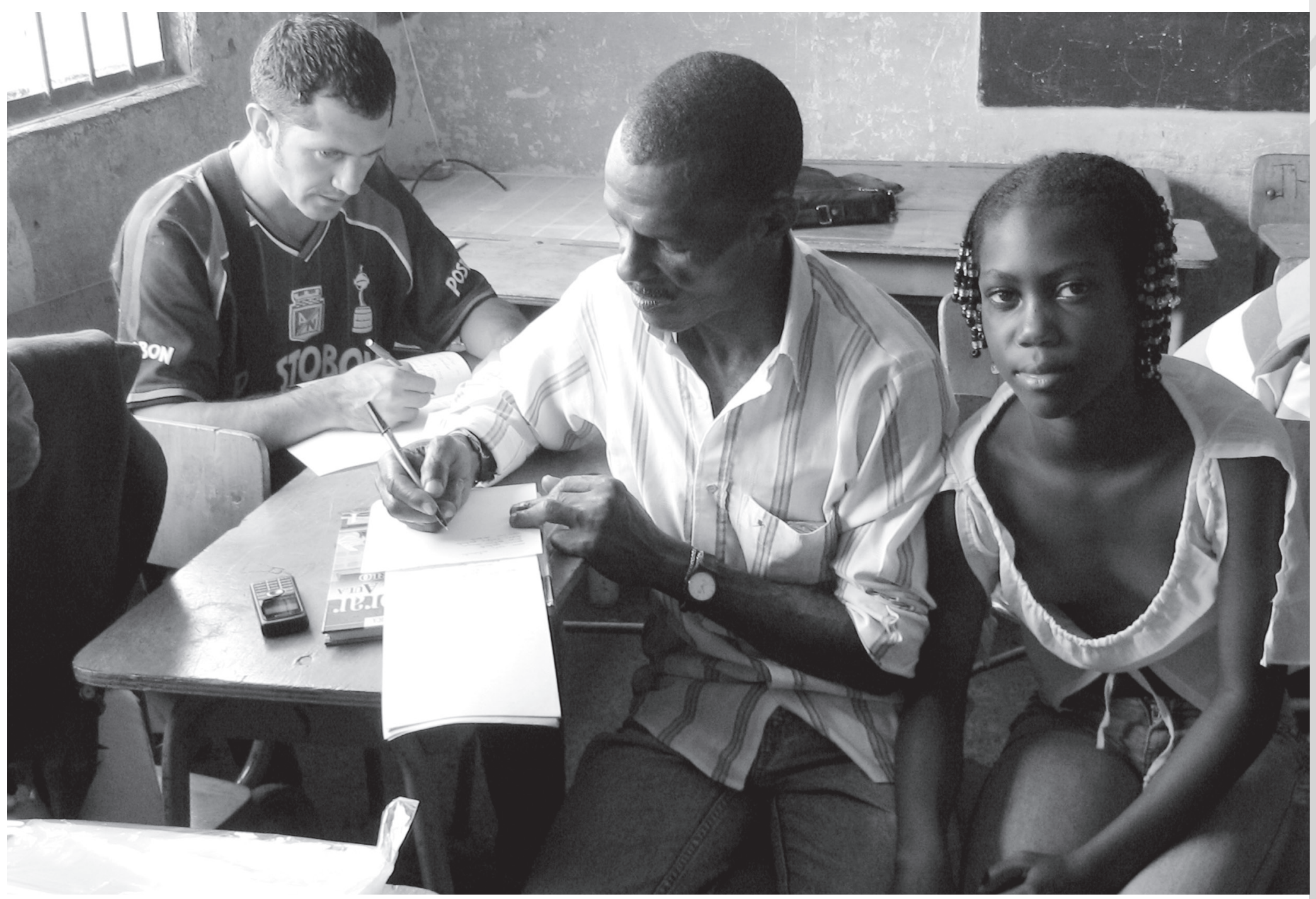

Fotografía. Centro de Memorias Étnicas de la Universidad del Cauca 